\title{
Carl Schmitt y el realismo político
}

Carl Schmitt and the political realism

\author{
Carlo Galli ${ }^{1}$ \\ Traductor: Bruno Vendramin ${ }^{2}$
}

\section{Resumen}

En este artículo el autor defiende una particular posición de realismo político al cual denomina "crítico", distanciándose de la acepción convencional del concepto. Seguidamente, analiza qué entendió Carl Schmitt por realismo, cuál fue su concepción de política y hasta dónde llega la capacidad crítica de su pensamiento. Finalmente, concluye que el realismo de Schmitt no es lo suficientemente autocrítico por no cuestionar sus propias categorías, por lo que su pensamiento vale como ejemplo concreto, en un contexto histórico determinado, que invita a reflexionar sobre el realismo político más allá de Schmitt.

Palabras clave: Realismo político - Carl Schmitt - crítica.

\section{Abstract}

In this article, the author defends a particular position of political realism, which he calls "critical", distancing himself from the conventional meaning of the concept. Next, it analyzes what Carl Schmitt understood by realism, what his conception of politics was and how far the critical capacity of his thought reaches. Finally, he concludes that Schmitt's realism is not self-critical enough for not questioning his own categories, so his thought is worth as a concrete example, in a given historical context, which invites us to reflect on political realism beyond Schmitt.

Keywords: Political realism - Carl Schmitt - critique.

\section{1. ¿Cuál realismo?}

Me gusta creer que mi modo de pensar la política pueda ser definido (lo ha sido) "realismo crítico." Ahora expongo los motivos por los cuales me distancio del realismo que definiré acrítico y, en definitiva, no realista.

\footnotetext{
Recibido: 30 de mayo de 2021 Aceptado: 4 de junio de 2021 Publicado: 8 de julio de 2021

${ }^{1}$ Módena, Italia, 1950. Graduado en Filosofía por la Universidad de Bolonia, fue profesor asistente de Historia de las Doctrinas Políticas y profesor asociado de Historia del Pensamiento Político Contemporáneo en la Facultad de Ciencias Políticas de la Universidad de Bolonia, de la que también fue director. De 1985 a 1990 estuvo en el consejo de redacción de la revista Il Mulino y de 2006 a 2009 formó parte de la dirección. En 1987 fue uno de los fundadores de la revista Filosofía política, de la que es director. De 2006 a 2012 fue presidente del consejo editorial de la editorial Il Mulino. De 2008 a 2012 fue presidente de la clase de Ciencias Morales de la Academia de Ciencias de Bolonia. Sus intereses de investigación se han orientado al pensamiento político moderno y contemporáneo. Entre sus últimas obras se encuentran: Platone, la necessità della politica (2021), Forme delle critica (2020), Sovranità (2019), Marx eretico (2018), Democrazia senza popolo. Cronache dal parlamento sulla crisi della politica italiana (2017).

${ }^{2}$ Correo electrónico: brunovendraminn@gmail.com ID https://orcid.org/0000-0003-3414-0637
} 
Nacido -junto a su opuesto, el idealismo- al interior de la disciplina politológica de las relaciones internacionales, el término "realismo político" (Portinaro, 1999; Campi y De Luca, 2014) comparte con la ciencia política algunas debilidades epistemológicas: la primera es que exista una realidad "ahí afuera", que ésta realidad sea inestable y conflictual, y que el mundo intelectual se divida entre quien la acepta como quien piensa que se la pueda cambiar. En esencia, una oposición entre ser y deber ser (posiciones premodernas, como el tomismo, son realistas en el sentido que suponen una realidad objetiva intrínsecamente ordenada y aquí el deber ser significa conocer y respetar la estructura lógica, ética y ontológica de la realidad).

La segunda debilidad epistemológica radica en suponer una sintonía entre naturaleza humana individual (psicológica) y naturaleza humana colectiva (el Estado), una convergencia entre antropología y política. Sintonía y convergencia bajo la señal de la inestabilidad, de la agresividad, de la peligrosidad de los individuos y los grupos humanos -todas características "naturales" y objetivas, cuya modificación es imposible, indeseable o inútil, o se consigue a través del ejercicio de rígidas disciplinas individuales y colectivas. Los "hombres rey" de Maquiavelo y la "vida corta, miserable, brutal y breve" de Hobbes -en suma, la antropología negativa y pesimista- como fundamento de formas políticas autoritarias. Naturalmente, a este respecto los idealistas que comparten con los realistas las debilidades de las cuales hablamos sostienen al contrario antropologías en diverso grado positivas.

La tercera debilidad es que el realismo, a partir de estos presupuestos, pasa a buscar y a encontrar leyes naturales o regularidades "objetivas" del comportamiento y de desarrollo tanto individual como colectivo, relativas a la ontogénesis y a la filogénesis (etología, psicología de las masas, etc.). El realismo culmina en el darwinismo social y político, en la selección del más apto a competir en un juego natural y mortal elevado a verdadera esencia del hombre y de la política.

La cuarta debilidad es que estos parámetros llevan a la construcción de una familia intelectual -los realistas políticos, precisamente- que contiene de todo: Tucídides, Maquiavelo, Hobbes, Mosca, Pareto, Schmitt, Aron, Miglio (pero se podría y debería agregar San Agustín, Donoso Cortés, Hegel, Spencer, Marx, Lenin y hasta Hitler). Una familia cuyos rasgos comunes son extremadamente frágiles y consistiría en la oposición contra pensadores idealistas, ingenuos, utopistas, formalistas, "liberales": Moro, Vitoria, Locke, Rousseau, Kant, Kelsen. Mientras que es evidente que las divergencias estructurales y categoriales entre los realistas son totales, radicales, inconciliables y lo mismo vale para los idealistas.

La quinta debilidad, finalmente, es que la categoría de realismo alude, a veces conscientemente $\mathrm{y}$ a veces inconscientemente, a una serie de oposiciones todas ideológicas y todas reversibles o discutibles: además de aquella entre ser y deber ser, está la de orden y libertad, entre coacción y espontaneidad, entre guerra y paz, el límite entre mal y bien, naturaleza y espíritu, entre derecha e izquierda, desigualdad e igualdad, hechos y valores, 
conservación y progreso, seriedad y juego. Donde el realismo es el primer término y el idealismo el segundo. Es decir, donde el realismo es la defensa de lo existente en su dureza y el idealismo es el esfuerzo de superarlo -vano para los realistas, útil y necesario para los idealistas- (mientras en realidad el primer ejemplo de prosa ática, el Pseudo-Jenofonte, es tan realista como aliado contra lo existente: la democracia ateniense).

En verdad, la realidad política es una construcción, una selección de experiencia, un montaje de causas y efectos; no está "ahí afuera" sino que es interna al pensamiento, y es interna a una lucha de pensamientos que una $y$ otra vez asume perfiles diferentes. Realismo es un nombre que nace de un conflicto de ideas y de posiciones prácticas en un tiempo determinado sobre un problema determinado contra adversarios determinados. Los politólogos realistas americanos estaban movidos por una polémica anti-wilsoniana (anti-universalista) que los llevaba a interpretar las relaciones internacionales como relaciones de fuerzas inevitables entre entidades políticas (relaciones a su vez interpretadas de diversas maneras y orientadas hacia un orden). Cada vez la realidad es re-interpretada, cada vez las leyes de la política son identificadas con propósitos polémicos. Aquí verdaderamente la realidad es una acumulación de experiencias (Nietzsche, 1977).

En Tucídides realismo es la lucha contra el mythos y la narración indirecta y fabulosa de los hechos; en Maquiavelo es la lucha contra la moral tradicional antigua y medieval aplicada a la política; en Hobbes es la lucha contra toda la tradición antigua y medieval por una política científica; en Hegel es la lucha contra el iluminismo y el liberalismo; en Marx es la lucha contra Hegel y contra la economía política; en Mosca es la lucha contra el igualitarismo democrático; en Schmitt es la lucha contra el universalismo jurídico-moral.

En cada una de estas posiciones -de los "realistas" y los "idealistas"- hay tanto un ser cuanto un deber ser como una polémica. En Maquiavelo el ser es la conflictividad y la agresividad humana (la lucha entre los Grandes y el Pueblo) y el deber ser es la redirección de esta conflictividad, que nace de la avaricia (de la posesión), hacia objetivos políticos expansivos (la virtud) y expansionistas (la guerra), con el fin de provocar cierta eficacia política en una Italia demasiado débil y dividida. En Hobbes el ser es el materialismo y el individualismo posesivo, junto a la guerra (en suma, el estado de naturaleza) y el deber ser es la salida del estado de naturaleza y la construcción del Estado político como dispositivo eficaz de paz, de garantía de la propiedad y de salvación humana y supra-humana. En Kant el ser es la insociable sociabilidad, el leño torcido de la humanidad que convive con el deber moral y con la posible interpretación de la naturaleza y de la naturaleza humana hacia una convivencia universal en el derecho. En Hegel existe el ser como dialéctica, como presencia impulsora del límite y de lo negativo en el corazón de lo real, y existe el deber ser como obligación de estar a la altura de las posibilidades cognoscitivas y prácticas que el tiempo ofrece (no se puede ser mejor que el tiempo de uno, pero se debe estar en el tiempo de uno de la mejor 
manera). En Marx existe el ser (el capitalismo) y el deber ser (develar las contradicciones reales para liberar la naturaleza humana cosificada). En Donoso existe el ser (la nulidad de la criatura humana, su necesidad de autoridad) y el deber ser (la lucha contra la modernidad y sus consecuencias). En Mosca existe el ser, la necesaria estructura elitista de la política, y el deber ser (la obligación de reconocerla y manejarla en clave anti-socialista). En Schmitt existe el ser, lo político, y el deber ser (la coacción a la forma política concreta), en lucha contra Versalles, Ginebra y Weimar (como él mismo dice).

Estos son solo ejemplos del hecho de que en cada autor hay una realidad, un ideal, una lucha. Y, por lo tanto, más en general, en lugar de construir la categoría de realismo (y de idealismo) y poner dentro a este o aquel autor que es un movimiento con sentido didáctico y exterior, pero no restituye la realidad de un acto intelectual- es mejor observar cuál es la concreción histórica en la cual cada autor se mueve, entender en cada uno de los autores qué cosa significa -y por cuáles motivos (y contra quién)- la palabra realidad y la palabra política.

En positivo, realismo (y "realismo crítico" es la determinación más eficaz) es una posición epistemológica y política compleja que exige un análisis de la experiencia histórico-política lo más extensa posible en la cual las ciencias sociales sean utilizadas, pero también vayan más allá de su descriptividad para capturar aquello que es radical y distintivo en una etapa histórica; a la extensión debe acompañarse la intensidad, la pendiente vertical: la actividad teorética de la crítica. Al mismo tiempo, la crítica debe someterse a la autocrítica, es decir, debe ser consciente de la propia determinación y condicionalidad; debe, por lo tanto, saber que al fondo hacia la cual tiende no está la Verdad sino un núcleo de relaciones sujetas a diferentes interpretaciones $\mathrm{y}$, sobre todo, un nudo de contingencias y de contradicciones concretas, pero no estables ni calculables. Esta es la "realidad" inestable (pero efectiva) del "realismo crítico"; una realidad nunca del todo plegable ni neutralizable en un logos, en una técnica o en una moral. Una realidad que tiene un inicio y un fin concreto: la propiedad privada y la libertad del racionalismo liberal, la posición de clase y la historia del pensamiento marxista (en el caso de Schmitt, la contingencia absoluta).

El realismo, entonces, rechaza el deber ser (la norma universal) en el momento del análisis: busca en la concreción histórica el inicio, el origen y el fin. Y se diferencia - cada vez, de diferentes maneras- del idealismo precisamente como lo concreto de lo abstracto, del mal universal que golpea sobre lo concreto como una Ley vacía (y del mal particular, que cree ser autosuficiente y nada sabe de sus causas y orígenes). Y este es un punto central, pues es central que la actuación del realismo es incompleta si prescinde de la lucha contra otras posiciones -de las cuales denuncia la condicionalidad inconsciente, su carácter ideológico.

Como se observa, el descubrimiento de leyes y la antropología negativa, la defensa de lo existente, están fuera de este horizonte o, mejor, solo son formas de auto-legitimación de ésta o aquella realidad histórico-política 
concreta. En cambio, no está afuera la proyección, inevitable como la condicionalidad, la concreción y la polemicidad; la proyección nace, en efecto, de la adhesión misma a la realidad (en el sentido antes expuesto): si la adhesión es crítica, si es condicionada (como es inevitable) está también orientada, dirigida a un fin. Por lo tanto, el realismo crítico implica no solo la autocrítica sino también el deber ser; es autocríticamente consciente de ello. Pero, al menos, está siempre ocupado en indicar cómo el deber ser puede nacer del ser, cómo es el desarrollo no necesario pero posible de contradicciones, eventos, procesos y tensiones concretas que constituyen la trama de la realidad. La proyección del deber ser incondicionado, de una fantasía consolatoria, de una racionalidad absoluta y universal no forma parte del realismo crítico; como no forma parte (aunque pueda existir) la clausura dogmática del presente, la ausencia de imaginación. La limitación que el realismo crítico no puede eludir está dada por el cálculo de los costos reales del deber ser que inevitablemente tiene en sí; y por el cálculo de los pasos históricos necesarios para realizarlo, así como la identificación de los sujetos que se supone puedan ser los portadores. Además de radical, el realismo crítico es responsable: responde a la pregunta de “¿qué hacer?” privado de certezas dogmáticas y abierto a la contingencia.

En este punto, hay que preguntarse cuál es el concepto de realidad de Schmitt; cuál es el concepto de política; dónde está la capacidad crítica de su pensamiento y hasta dónde llega.

\section{Schmitt - la estructura de la realidad}

La interpretación que da Schmitt de la realidad está en su teología política y es hostil al individualismo y a la subjetividad liberal (Schmitt, 2021) pero también al normativismo y a la economía política. Esta hostilidad es deducida del hecho de que él ve en estas posiciones la pretensión de someter la realidad histórico-política a una norma universal, a una interpretación y a una proyectualidad simplificadora.

Realidad para Schmitt es el doble rostro de la Modernidad, la coacción al orden y la imposibilidad del orden; y este doble lado de la Modernidad es visible gracias a la teología política, la imagen de época que mantiene unida la secularización (los conceptos políticos son conceptos teológicos secularizados, son la permanencia, entre otros aspectos, del pensamiento del orden) con un resto originario y deficitario, no racionalizable, una estructural carencia de sustancia que también es una coacción al orden.

Schmitt parte de la cuestión de la Rechtsverwirklichung, de la realización práctica de la idea jurídica de orden sobre el impulso de la más tradicional línea teológico-política que se despliega entre los contrarrevolucionarios católicos de una parte y de Thomas Hobbes por la otra (Schmitt, 1972, pp. 27-86; Schmitt, 2011). Schmitt, enemigo de la Gran Separación liberal moderna entre religión y política, asume que la modernidad es la secularización de la tradición teológica, pero la clave de su posición no es solo la analogía entre soberanía y omnipotencia de Dios (la 
analogía, de origen contrarrevolucionaria, entre formas de la metafísica y formas políticas) que incluso él acepta, sino sobre todo aquella entre decisión y milagro. La teología política schmittiana comprende la estructura lógica de las legitimaciones de la modernidad como una re-utilización política de los conceptos teológicos en un contexto marcado originariamente por la Nadade-Orden, de la ausencia de la trascendencia y de todo orden bien fundado; en consecuencia, decisión y milagro son la ruptura de la norma.

Sin embargo, la soberanía es solo parcialmente análoga al milagro: en efecto, su acción, la decisión, se da en un tiempo, la modernidad, en la cual el orden está ausente y no tiene ninguna base ontológica: a diferencia del orden tradicional, donde el milagro golpea solo momentáneamente (Schmitt, 1975, p. 151), la excepción es la norma de lo Moderno; no es ocasional sino originaria y funciona dentro de lo Moderno como principio de indeterminación y, al mismo tiempo, como coacción a la forma. Y la decisión, la acción política adecuada a la excepcionalidad de la política moderna, no solo suspende y subvierte los órdenes, sino que también se encarga de fundarlos -en cuanto están suspendidos sobre la nada. Después de todo, el orden es el verdadero milagro en la época de la normalidad de la excepción: el orden está dispuesto en formas sucesivas que son análogas a las de la teología con la diferencia decisiva que su centro está vacío de sustancia y, en consecuencia, todos los órdenes son inestables, infundados. Son mediaciones suspendidas en la nada. Teología política, para Schmitt, es a la vez necesidad de forma y desencanto de ella. Es en referencia a la trascendencia ausente que Schmitt comprende la inmanencia, su estructura, sus exigencias: teología política es para él descubrir el punto ciego de lo Moderno, su incompletitud, su inmediatez, su contingencia y, al mismo tiempo, la potencia de la falta de trascendencia que se manifiesta en la coacción moderna a destruir como a construir, es decir, a quedar en el interior de la metafísica que es siempre negada.

Concretamente, la normalidad de la excepción es la permanencia de lo político como relación amigo/enemigo y significa, sobre el contorno político, que el Estado es todo menos estable, pero no tanto porque esté atravesado por la dialéctica socio-económica sino porque es originariamente indeterminado por lo político, es decir, por la excepción y la decisión, por el poder constituyente frente a la revolución. Lo concreto que Schmitt persigue en toda su vida son los órdenes políticos específicos y decisivos (y, por lo tanto, disueltos de la perspectiva del progreso histórico) que solamente la modernidad permite. A diferencia de Nietzsche que lo rechazó por débil, Schmitt descubre y vuelve operativo y productivo el nihilismo de la modernidad.

En la teología política está -más que en la antropología política negativa (la creencia en una naturaleza buena o mala del hombre es el indicador de la conciencia de lo político, no la fundación científica de la política) (Schmitt, 2011, pp. 87-208)- la raíz del realismo de Schmitt; un realismo que no se manifiesta en la identificación de leyes o regularidades naturales sino en la 
indeterminación de todo discurso y estructura de orden y, al mismo tiempo, es coacción a la producción de orden. Un realismo que nace de una idea inestable de la realidad y que polemiza contra la potestas indirecta de los moralismos y contra las utopías de juridificación total de la realidad.

El orden no nace del sujeto individual y tampoco del soberano: de hecho, es evidente que el sujeto del actuar político (el soberano) es indeterminado y ocasional, es la función que activa la indeterminación estructural del orden («soberano es quien decide sobre el estado de excepción»); y es igualmente evidente que aquí el Mal es la inconsciencia de la estructura teológico-política del orden moderno y la inercia y la ineficacia que ello implica: en el libro sobre el parlamentarismo el racionalismo liberal está, en efecto, inscripto en una metafísica inconsciente de la discusión similar al eterno diálogo del ocasionalismo romántico (Schmitt, 2021; Schmitt, 2004). Es decir, Mal es la inconsciencia de los límites del logos individualizante y neutralizante, es la debilidad política de la potencia técnica; Bien es la fuerza concreta que rompe y crea el orden, es decir, la decisión (que, en su espasmo nihilista, también es parte del problema) y, en la etapa posterior, el Nomos que corta y toma posesión, pero que también es ordenamiento concreto -no neutral sino orientado, eurocéntrico (Schmitt, 1991).

En consecuencia, para Schmitt no es posible pensar lo Moderno, como hacía Hegel, como la evolución progresiva de la sustancia que se aprende en formas siempre más adecuadas, de la religión a la filosofía. Sobre este punto hay un hiato insuperable entre el jurista católico y el filósofo luterano; lo Moderno no permite ni promete conciliación sino conflicto permanente. Pero a la dialéctica protestante Schmitt no opone ni la neutralizante autointerpretación racionalista de la modernidad como laicización ni el fundamentalismo católico. Su posición es la de una continuidad formal y una discontinuidad sustancial entre religión y política (entonces, opuesta a la de Hegel; por lo demás, Schmitt está lejos de Marx, cuya mediación materialista y dialéctica tiene como objetivo una inmediatez conciliadora, es decir el comunismo, y solo tangencial respecto a Weber y su individualismo metodológico); $\mathrm{y}$, a diferencia incluso de Hobbes, para Schmitt el vaciamiento moderno de la religión, su persistencia como esquema trascendental del orden político no da vida a un orden racional tendencialmente estable.

Schmitt intenta salir en la posguerra del paradigma decisionista y nihilista que su teología política le entrega (con muchos otros resultados, incluso la etapa nazi puede ser así interpretada): pero ciertamente no sale de la teología política ni de la metafísica. A este intento pertenece la Teología política II con la refutación de la refutación de Peterson -para Schmitt la teología política no puede ser liquidada teológicamente porque corresponde a un ámbito metafísico y político, no teológico- (Schmitt, 1970) y también la segunda interpretación de Hobbes como cristiano, después de una primera interpretación (1938) del Leviatán decisionista y positivista (Schmitt, 2011, pp. 35-128) que allí había visto, principalmente, un mito o una máquina: el "cumplimiento de la Reforma" (Schmitt, 2011, pp. 129-165) realizado por 
Hobbes es para Schmitt (1965) la superación de la mediación pontifical católica y de su resto que es la potestas indirecta, e incluso la superación política del individualismo moderno en su forma más desestabilizante (la reserva interior judía y luterana); pero también es la permanencia de la trascendencia no como fundamento de la política, sino como su ausencia, como su horizonte de sentido. La política moderna solo puede ser cristiana, solo teología política. Y solo puede perder, progresivamente, la conciencia de su origen.

Ya desde la primera mitad de los años cuarenta Schmitt ha introducido la afortunada imagen del katechon al principio interpretada por él como poder político territorial y continental opuesto a las potencias técnicasmarítimas-capitalistas ignorantes de decisión, de fronteras, de concreción y abiertas al poder indirecto, a lo ilimitado, al uso político discriminatorio (la guerra justa) de la moral y del derecho; posteriormente, como concepto y figura de un poder que no solo detiene el Mal en la historia sino también que vuelve posible la historia en general como alternativa respecto a las dinámicas progresivas de la tecnificación, de la democratización del mundo y de su unificación comunista o capitalista. Contra el progreso que aniquila y vacía la historia, el katechon ya no es, en la etapa final del pensamiento de Schmitt, una forma histórica específica sino el cristianismo que con su axialidad -que se incardina en el concreto nacimiento de Cristo- podría salvaguardar la historia misma sustrayéndola de las derivas entrópicas del automatismo y del caos; es, entonces, la conciencia de la insuperabilidad de la teología política (conciencia de que la historia, sin embargo, está terminando). En definitiva, Schmitt sigue siendo un pensador del origen, pero ahora el origen no es más la decisión sino más bien la encarnación.

Si la teoría del Nomos es el fruto más maduro del esfuerzo de Schmitt de salir de la inestable realidad del decisionismo, el libro sobre el Nomos, más allá de su utilización contemporánea, es un libro epimeteico que recorre $e x$ post la historia moderna bajo el signo de un fracaso. La teología política con su doble impulso a la decisión y a la forma le parece al viejo Schmitt completamente declinada.

Aquí su realismo se vuelve nostalgia.

\section{Schmitt - guerra y política}

Si realismo es insistir sobre el rol central que la guerra tiene como fenómeno político -aún sin darle una valoración positiva, se entiendeSchmitt es sin duda realista. La palabra clave a este respecto es co-pertenencia entre guerra y política (es decir, lo político).

Pero esta co-pertenencia tiene causas históricas y metafísicas. Es la crisis de la estatalidad moderna y, por lo tanto, también de la distinción entre paz y guerra y del control de la política sobre esta última, que va a constituir el problema político que interesa a Schmitt (1972, pp. 193-203; 2015a y2015b).

El significado del concepto de lo político como relación amigo/enemigo entendido por Schmitt como el origen de la política radica en que en las 
asociaciones humanas suficientemente intensas dignas del nombre de políticas hay, además de un principio de unión, también un principio de disociación, de hostilidad y de exclusión interna antes incluso que externa; la disposición real a ser asesinado y asesinar es la característica y el estigma de lo político, de su seriedad (Schmitt, 1972, pp. 116-118). La guerra es la anomia que está al interior del Nomos como su origen: esto no solo implica la primacía de la guerra civil sobre la guerra exterior, sino que reconoce a las instituciones políticas como nacidas de un conflicto que debe ser controlado -del cual, por lo tanto, debe existir conciencia- y que no puede ser eliminado o neutralizado del todo, como es el objetivo del racionalismo (incluso la principal reserva de Schmitt sobre Hobbes está en su concepción del Estado como máquina técnica-racional).

No hay que dejarse llevar por la nostálgica descripción de la forma de guerra moderna, de la clara distinción entre paz y guerra derivada de la distinción soberanía-estatal entre interior y exterior, que Schmitt traza a partir de los últimos años del treinta y que lleva a término en El Nomos de la tierra (Schmitt, 1972; 1991, pp. 161 y ss.); la guerra limitada clásicamente al enfrentamiento entre fuerzas armadas de uniforme, expresión de los Estados europeos, es una breve excepción histórica (muy utilizada, sino exagerada, por Schmitt). Es en la crisis del siglo XX de las instituciones neutrales de la modernidad que emerge precisamente para Schmitt la inmanencia del desorden y del conflicto respecto a la paz que es el origen auténtico e ineludible de la política. Que es un problema, pero también es la verdad más radical de la que puede echar mano.

La política como la ve Schmitt es energía total; al menos en potencia, es un paroxismo omnicomprensivo que no deja subsistir ninguna de las distinciones clásico-modernas (paz y guerra, civil y militar, público y privado, pueblo e instituciones, Estado y sociedad) y da lugar, por tanto, a la política total como a la guerra total. Es decir, Schmitt sabe que la política contiene guerra y que el orden solo puede ser tal si acepta el desorden y se estructura a su alrededor. Solo negándose el orden político puede, precariamente, afirmarse. Y aquí, en el primado lógico de la guerra civil sobre la guerra exterior (sin embargo, no en la acepción maquiaveliana, sino más bien como el espejo inverso de la hobbesiana), se encuentra toda la distancia de Schmitt respecto a la forma clásica de Estado.

Ciertamente, Schmitt se plantea el problema de controlar, sin que jamás pueda ser abolido, el nexo guerra/política, de hacerlo una vez más concreto, productivo de forma política. Desde este punto de vista, Schmitt continúa los esfuerzos de Hobbes, de Hegel, de Clausewitz: los esfuerzos de pensar en sentido ordinativo la proximidad de guerra y política, más bien su inextricable co-pertenencia después del fracaso de sus intentos, es decir, en la crisis ya irreversible del Estado. Y, a pesar de la inversión categorial que presenta, en Schmitt también hay nostalgia de la estatalidad. En consecuencia, el objetivo de Schmitt es el de aprovechar precisamente los propósitos ordinativos de la imposibilidad del orden, esto es, del orden que acompaña al conflicto. Y a 
estos propósitos es orientada la presencia del soberano o del partido o del partisano -igualmente enemigo concreto, no absoluto (Schmitt, 2005)-, en función de aquello que Schmitt piensa practicable una y otra vez en el curso de su larga experiencia existencial y política: la acción política es el movimiento por el cual un sujeto político determina al enemigo para determinarse a sí mismo como amigo, se disocia para asociarse, excluye para incluir. El orden es posible siempre que conserve en sí mismo al desorden originario.

Por lo tanto, a diferencia de Jünger, Schmitt no atribuye rango ontológico sobrehumano e intrínsecas capacidades morfogenéticas al automovimiento del conjunto técnica/guerra. No hay, para él, la sustancia de actuar sino actores políticos determinados: el resultado de la acción no son sacrificios humanos sino la institución política o, en todo caso, una afirmación de orden también espacial (además de que para Schmitt en la guerra se trata del Ser, como para Heidegger).

Schmitt es, en efecto, el gran adversario del intento de remediar la crisis del Estado a través de la construcción del derecho internacional y la reducción del papel de la soberanía. La representación del espacio internacional como una unidad indiferenciada de la cual la guerra debe ser expulsada como un crimen, es producto, para él, de ignorar la indistinguibilidad originaria de guerra y política, que sin embargo permanece y además se agrava. Es por el olvido -a cargo de las potencias marítimas (Schmitt, 2002) y liberales anglosajones- del origen de la política (de lo político) que la política se hace aún más beligerante, y la guerra discriminatoria es por lo tanto aún más destructiva: "guerra justa" contra el enemigo criminalizado (Schmitt, 2008). En realidad, al realista político le preocupan los idealistas por más eficientes y más letales. Pero no es en la acción de policía internacional de entidades supranacionales que, para él, se debe buscar la solución al problema constituido por el hallazgo dramático del hecho de que guerra y paz no son más distinguibles; en cambio, sí es necesario convertirlo en el origen de un nuevo orden, de una nueva repartición mundial del espacio. Que está contenida en la idea schmittiana de Gran espacio (Schmitt, 2015, pp. 101187) -no obstante, desde el punto de vista de la relación entre guerra y política no es particularmente innovadora y reproduce lógicas tradicionales de estatalidad.

En consecuencia, Schmitt vuelve a proponer la discontinuidad moderna, no cualitativa, entre espacio interior y espacio exterior, entre ley y conflicto, entre paz y guerra, entre criminal y enemigo. Pero la suya es una restauración solo aparente: en realidad, tanto al interior como al exterior, el espacio está atravesado por la violencia, por lo que no es un espacio neutral o neutralizable, sino que está siempre orientado al conflicto y a la exclusión (y este es el sentido incluso de la teoría tardía del Nomos): un espacio que incorpora al conflicto en la política.

Si belicismo es pensar y practicar una política orientada a la guerra, Schmitt es, entonces, más que un belicista: su teoría contempla no sólo el fin 
del equilibrio entre guerra y política, sino también de su distinción categorial $\mathrm{y}$, a pesar de la estructura ordinativa neo-clásica de su pensamiento, abre grietas inquietantes sobre la difusión de la violencia dentro de la política.

La constante lucha contra el universalismo jurídico, que para él no es más que una concepción policial, moralista, criminalizante y discriminatoria de la guerra siempre la involucra a la concreción, confiada poco a poco a la decisión soberana, al Gran Espacio, a la guerra total: esta es para él una guerra integral -es decir, una guerra que involucra Estado, sociedad, ejército y partido, economía, política, ideología; en suma, todas las formas de existencia humana- pero no es discriminatoria porque se levanta contra un enemigo igualmente total y concreto (Schmitt, 2007, pp. 389-398). Es la guerra que implica todas las energías sin distinción entre Estado y sociedad.

La guerra total como fue pensada y dirigida por el nazismo fue en cambio brutalmente discriminatoria, no integral sino bestial, no la manifestación de una identidad fuerte y segura de sí que afronta a sus propios enemigos sino de una indistinción caótica, de un delirio angustioso. A la agudeza de Schmitt -capaz de comprender que el enemigo es, en la modernidad, factor de forma política y que éste, a la inversa, está atravesado por lo político, por el conflicto- se le escapó que la Alemania totalitaria reproducía en sí misma, potenciándola, la anormal situación intermedia, la zona gris de indistinción entre paz y guerra, la interpretación discriminatoria y moralista del conflicto, la criminalización y la deshumanización del enemigo, cuya sustancia social y biológica perseguía la destrucción. Schmitt fue ciego delante de esto y se mantuvo inmóvil ante la denuncia del hecho de que fueron los aliados liberales, democráticos y comunistas unidos por el universalismo, aunque rechazado de forma distinta- quienes condujeron a una guerra total discriminatoria contra Alemania (Schmitt, 1991, pp. 429-431) y a practicar la criminalización del enemigo vencido; y al arrepentimiento -incoherente con la esencia de su pensamiento- por el jus publicum europaeum, ya quedado en el pasado con su conceptualidad política clara y distinta.

\section{Conclusión}

Se podría interpretar a la luz del realismo la posición de Schmitt entre 1931 y 1932 en la crisis de Weimar (Schmitt, 1981; Schmitt, 2018). Él fue realista porque fue capaz de una mirada politológica, jurídica e históricateórica radical: una mirada que le permitió formular diagnósticos y categorías que entraron en el debate contemporáneo, compartidas también por autores de orientación opuesta. Vio la desesperante situación del parlamento y del Estado alemán sin velos ideológicos antidemocráticos: así, su esfuerzo pasó por la defensa del orden institucional de Weimar que siempre vio como vinculante, pero también como expresión de una verdadera decisión soberana del poder constituyente del pueblo alemán. Una defensa que él quiso encomendar -y aquí también fue realista- no a los partidos (que eran el problema en la polarización extrema) sino al presidente, en torno al cual quiso construir un "Estado de los Presidios" necesariamente autoritario, pero 
con capacidad de dejar a fuera a Hitler (y a los comunistas). En cambio, fue iluso al pensar que había alguien que quería salvar a Weimar, aunque sea al alto precio que él proponía; en realidad, todos los poderes fuertes de Alemania pasaron hacia Hitler apenas Hindenburg lo designó canciller (con el objetivo de mantenerlo a raya), y Schmitt también se encontró colaborando con el nuevo orden tomando nota del suicidio de la república.

Oportunismo, arribismo y cinismo marcan este pasaje; que se explica sobre todo por el hecho de que en el corazón del pensamiento de Schmitt hay un espacio vacío (la excepción) que puede ser llenado de todo contenido (el ocasionalismo de Schmitt); pero desde luego no es el realismo (si no en la acepción más obvia de reconocimiento del acontecimiento consumado por otros) el que inspira su adhesión al nazismo. Que, en todo caso, fue precedida de una ilusión.

Sin embargo, en conclusión, aunque afectado de nostalgia, ceguera, ingenuidad, el pensamiento de Schmitt es realista y no en sentido banal, objetivo (las leyes de la política) o ideológico (la defensa de la tradición, la exaltación de la ley del más fuerte). Es realista porque intenta captar la contingencia, la concreción. Y, por lo tanto, está bien lejos de realistas como Hegel (en Schmitt no existe la dialéctica) y como Maquiavelo (que no conoce la teología política de la ausencia).

Pero naturalmente Schmitt (como ningún otro) no puede no sobreponer filtros a la realidad $\mathrm{y}$, de hecho, la contingencia es por él tomada como ausencia de la trascendencia por vía paradojalmente metafísica. Definitivamente, un potente correctivo al racionalismo y al pensamiento dialéctico (capaz a su vez de realismo, aunque de forma diferente, en torno a la propiedad o a la clase); un realismo tardo-moderno interno al pensamiento negativo.

Pero es un realismo que, si bien es radical, no es lo suficientemente autocrítico. Schmitt vive y muere al interior de su realismo sin cuestionar jamás los ejes categoriales. De la trampa metafísica ausencia de ordencoacción al orden no sale nunca. De aquí, precisamente, la nostalgia y la ceguera. Pero también se debe decir que el no saber saltar sobre la propia sombra, el no poder salir de la propia piel que exigimos a Schmitt no es una empresa fácil. Ciertamente, él tampoco ha querido intentarla. Y, por esto, Schmitt vale como un instrumento y no como dogma; no como última palabra del realismo crítico sino como ejemplo concreto, históricamente determinado, que nos empuja a pensar (incluso) con Schmitt más allá de Schmitt.

\section{Referencias bibliográficas}

CAMPI, A y DE LUCA, S. (2014). Il realismo politico. Figure, concetti, prospettive di ricerca. Soveria Manelli: Rubbettino.

NIETZSCHE, F. (1977). La gaia scienza. Milano: Adelphi (Trad. castellana: La gaya ciencia. Madrid: Akal, 2001). 
PORTINARO, P.P. (1999). II realismo politico. Roma-Bari: Laterza (Trad. castellana: El realismo político. Buenos Aires: Nueva visión, 2007).

SCHMITT, C. (1991). El nomos della terra nel diritto internazionale dello "jus publicum europaeum". Milano: Adelphi (Trad. castellana: El Nomos de la Tierra. Granada: Comares, 2003).

SCHMITT, C. (2008). Il concetto discriminatorio di guerra. Roma-Bari: Laterza.

SCHMITT, C. (1981). Il Custode della Costituzione. Milano: Giuffre (Trad. castellana: La polémica Schmitt/Kelsen sobre la justicia constitucional: El defensor de la Constitución versus ¿Quién debe ser el defensor de la Constitución? Madrid: Tecnos, 2019).

SCHMITT, C. (1975). La dittatura. Dalle origini dell'idea moderna di sovranità alla lotta di classe proletaria. Roma-Bari: Laterza (Trad. castellana: La dictadura. Madrid: Alianza, 2013).

SCHMITT, C. (2015a). La guerra d'aggressione come crimine internazionale, Bologna: Il Mulino (Trad. castellana: El crimen de guerra de agresión en el derecho internacional. Buenos Aires: Hammurabi, 2006).

SCHMITT, C. (2004). La condizione storico-spirituale del'odierno parlamentarismo. Torino: Giappichelli (Trad. castellana: Los fundamentos históricos-espirituales del parlamentarismo en su situación actual y la polémica con Thoma sobre el significado de la democracia. Madrid: Tecnos, 2018).

SCHMITT, C. (1972). Le categorie del 'politico'. Bologna: Il Mulino (Trad. castellana: El concepto de lo político. Madrid: Alianza, 2009).

SCHMITT, C. (1932). Legalita e legittimita. Bologna: Il Mulino (Trad. castellana: Legalidad y legitimidad. Granada: Comares, 2006).

SCHMITT, C. (2007). Posizioni e concetti. In lotta con Weimar-GinevraVersailles, Milano: Giuffré.

SCHMITT, C. (2021). Romanticismo político. Bologna: Il Mulino (Trad. castellana: Romanticismo político. Quilmes: UNQ, 2001).

SCHMITT, C. (2015b). Stato, Grande spazio, Nomos. Milano: Adelphi.

SCHMITT, C. (2011). Sul Leviatano. Bologna: Il Mulino (El Leviatán en la teoría del Estado de Thomas Hobbes. Granada: Comares, 2003).

SCHMITT, C. (1992). Teologia politica II. La leggenda della liquidazione de ogni teologia politica. Milano: Giuffre (Trad. castellana: Teología política. Madrid: Trotta, 2009).

SCHMITT, C. (2005). Teoria del partigiano. Milano: Adelphi (Trad. castellana: Teoría del partisano. Madrid: Trotta, 2013).

SCHMITT, C. (2002). Terra e mare. Milano: Adelphi (Trad. castellana: Tierra y mar. Madrid: Trotta, 2019). 